\title{
Karakterisasi Morfologi dan Anatomi Tanaman Manggis dan Kerabatnya (Garcinia spp.) di Taman Buah Mekarsari
}

\section{Morphological and Anatomical Characterization of Mangosteen Plants and Its Relatives (Garcinia spp.) in Mekarsari Fruit Garden}

\author{
Departemen Biologi Fakultas Matematika dan Ilmu Pengetahuan Alam, Institut Pertanian Bogor, Kampus Darmaga, \\ Bogor, 16680
}

RR. SYAFIRA NIDYASARI, HILDA AKMAL*, NUNIK SRI ARIYANTI

Diterima 3 Maret 2018 /Disetujui 30 Juli 2018

\begin{abstract}
Mangosteen (Garcinia mangostana)cultivation has problems in terms of fruit quality and rooting system. This problem is solved by Mekarsari Fruit Garden by developing technology of double root stock seedling that is by combining two mangosteen seedling into one plant through the pasting process. Characterization of the collection of mangosteen plants and its species of relatives (Garcinia spp.) is needed to seek a superior characters used for technology of double rootstock seedlings, cultivar development, and management and preservation of mangosteen germplasm. This study aims to record and compare morphological and anatomical characters of mangosteen and its relatives collected in Taman Buah Mekarsari. The study was caried out by collecting sample and characterizing the morphological structure using mangosteen descriptor, observing the leaf paradermal anatomy, and collecting secondary data. Observation on the morphological characteristics of mangostana (G. mangostana) and its relatives (G. celebica, G. dulcis, G. forbesii, and $G$. malaccensis) showed variations on the fruit characters, such as the shape is spherical, ovate or sperical flattened apex and base; the rind color is bright yellow, deep red, and bright red; the flavour is sour, sour sweet, or sweet. The anatomical character of the mangosteen leaf and four species of its relatives show the paracytic stomata on the abaxial surface only except on the leaf of $G$. forbersii, which is found on the abaxial and adaxial sustance, the epidermal cells are square to rectangular, the wall is straight or slighty winding except that of $G$. forbesii which is sharply winding or zig-zag.
\end{abstract}

Key words: Mangosteen, Garcinia, morphology, anatomy, characterization

\section{PENDAHULUAN}

Garcinia merupakan salah satu genus dari famili Gutiferae/Clussiaceae dan anggotanya tersebar luas di wilayah tropik dunia. Spesies-spesies dalam genus Garcinia mempunyai manfaat yang beragam, seperti penghasil buah yang dapat dimakan, minyak, dan obat (Jamal et al. 2001). Manggis (Garcinia mangostana) merupakan salah satu spesies dari genus ini, buahnya dikenal sebagai queen of fruits dan di Indonesia menjadi komoditas ekspor. Kulit buah manggis digunakan sebagai obat tradisional untuk anti-radang, anti-diare (Jamal et al. 2001) dan anti-kanker (Madury et al. 2012). Manggis memiliki banyak kerabat, tidak kurang dari 13 spesies kerabat manggis dijumpai di wilayah tropik Asia Tenggara dan India (Sulassih et al.2013). Beberapa kerabatmanggis seperti $G$. dulcis daunnya mengandung anti-mikroba (Phongpaicit et al. 2006) dan dapat dimanfaatkan sebagailarvasida nyamuk Culex quinquefasciatus dan Aedes aegypti (Hariani 2014), ekstrak kulit batang $G$. celebica mampu menghambat pertumbuhan bakteri gram positif maupun gram negatif(Jamal et al.2001), cabang dan ranting $G$. forbesii mengandung xantone

*Penulis korespondensi :

E-mail:hilda.akmal@gmail.com yang dapat digunakan sebagai anti-tumor, anti-jamur, anti-bakteri (Harrison et al. 1993), dan kulit buah $G$. malaccensis sebagai antimikroba dan antioksidan (Taher et al. 2012).

Produksi buah manggis mengalami kenaikan hingga 203.103 ton pada tahun 2015 dari sebelumnya 114.761 ton pada tahun 2014 (BPS 2017). Namun budidaya manggis saat ini masih mempunyai beberapa permasalahan seperti mutu buah yang tidak seragam atau tidak sesuai standar, sistem perakaran yang tidak kokoh, serta umur panen yang panjang pada tanaman yang diperbanyak melalui biji. Tanaman manggis yang berasal dari biji baru dapat dipanen buahnya pertama kali setelah berumur 15 tahun, karena masa juvenilnya yang panjang. Permasalahan budidaya tersebut dapat diatasi dengan perbanyakan secara vegetatif melalui pengembangan teknologi bibit manggis kaki ganda dan sambung. Prinsip teknologi kaki ganda yaitu menggabungkan dua bibit manggis menjadi satu tanaman melalui proses penempelan (TBM 2015). Teknologi tersebut menghasilkan bibit manggis dengan akar yang lebih banyak, sehingga meningkatkan penyerapan unsur hara. Teknik sambung memiliki prinsip yang berbeda yaitu menggunakan batang bawah dari kerabat dekat manggis yang memiliki sistem perakaran yang kuat. Karakterisasi manggis dan kerabatnya diperlukan 
untuk mencari karakter unggul yang dapat digunakan pada teknologi bibit kaki ganda, pengembanga kultivar unggul, dan dalam rangka manajemen pelestarian plasma nutfah manggis (Sinaga 2008). Karakterisasi juga diperlukan untuk mendapatka sumber data untuk analisis kekerabatan (Sulassi et al. 2013). Taman Buah Mekarsari mempunyai koleksi tanaman manggis dan kerabatnya, untuk produksi buah dan sebagai koleksi sumber genetik yang dapat dimanfaatkan dalam pengembanga kultivar unggul. Namun karakterisasi morfologi dan anatomi tanaman-tanaman tersebut belum dilakukan di Taman Buah Mekarsari. Penelitian ini bertujuan untuk mencatat dan membandingkan karakter morfologi dan anatomi koleksi tangkan manggis dan kerabatnya di Taman Buah Mekarsari

\section{BAHAN DAN METODE}

Waktu dan Tempat Penelitian. Penelitian in dilaksanakan pada bulan April 2016 hingga Janua 2017 di Kebun dan Laboratorium Biosari Taman Buah Mekarsari, serta Laboratorium EKO-SD Departemen Biologi FMIPA-IPB.

Alat dan Bahan. Bahan yang digunakan dalam penelitian ini yaitu lima spesies koleksi tanam mang gis dan kerabat lat dan bahan unk prepasi alat dan bah basah (daun dari lima spesies nanggis, tabung film dan alkohol $70 \%$ ), alat dan bahan untuk prepara dan pengamatan sayatan paradermal daun (aquades, HNO3 50\%, safranin 1\%,gliserin 30\%, kloroks, silet kaca objek, kaca penutup, pipet, pinset, mikroskop majemuk, image raster, dan kamera HDMI), ala untuk pengamatan morfologi (lup, mikroskop stereo, penggaris), alat pengukur padatan terlaru dan penimbang buah (refraktometer, timbangan digital) serta a tuntuk (rengukur kondisingkungan di kital), di kebun kaleksi (4 in l environmental, sc kamera digital, haga meter, meteran).

\section{Prosedur Penelitian.}

Penentuan dan Pengambilan Sampel. Sampe tanaman manggis dan kerabatnya untuk pengamata karakter morfologi diperoleh dari koleksi tanama di Taman Buah Mekarsari, meliputi lima spesies ( $G$. mangostana, G. malaccensis, G.dulcis, G. celebica, dan G. forbesii) masing-masing spesies terdiri ata 10 tanaman. Morfologi Tinggi tanaman diukur da leher akar hinge titik tumbuh tamaman, sedangk diamer diamer berdasarkan sampel tiga lembar daun untuk masingmasing tanaman sampel yang dilakukan pada daun masing tanaman sampel yang
Pengamatan Karakter Morfologi Tanaman. Karakter morfologi tanaman diamati mengikuti deskriptor manggis (IPGRI 2003). Karakter morfolog untuk deskriptor pertumbuhan tanaman yang dicata meliputi: umur tanaman, tipe perbanyakan, ting makan, tinggi tanaman, ing permukaa batang, tipe tajuk, pola percabangan perawaka pertumbuhan tanaman. Karakter daun yang diamat: warna daun muda, warna daun tua, susunan daun, panjang tangkai daun, lebar tangkai daun, panjang helai daun, lebar helai daun, bentuk daun, bentuk ujung daun, bentuk pangkal daun, tepi daun, permukaan atas daun, permukaan bawah daun, kenampakan ibu tulang daun, kenampakan pertulangan daun. Karakter bunga yang diamati: keteraturan berbunga durasi berbunga, kemelimpahan bunga, posisi bunga, pengelompokkan bunga, panjang tangkai, diamete penge bunga, jum an dan warna sepal, jumlah dan warn petal, jumlah berkas benang sari, jumlah benan sari per berkas, panjang pendukung benang sari (androfor). Karakter buah yang diamati: panjang tangkai, warna tangkai, bentuk buah, ukuran (diameter dan berat buah), warna buah matang, kemenarikan buah, keberadaan lobus kepala putik, ketebalan lobus kepala putik, warna lobus kepala putik, jumlah segmen buah, ketebalan kulit buah, ketebalan aril, tekstur aril, total padatan terlaru obrix, kualitas aril, aroma aril, rasa aril, kandungan air aril, warna aril. Karakter biji: tipe biji, wa biji, jum bij. biji, jumlah biji.

Pengamatan Karakter Anatomi Daun. Pengamatan dilakukan dengan membuat sediaan sayatan paraderma daun mengacu pada Sass (1951) yang dilakuka pajang tokasi daun, yaitu pangkal, tengah, dan (2016) Cara peubuatan sedian sayatan paraderm daun mengounan metode whole mount yaitu (1) lembar daun diambil dan difiksasi dengan alkoho 70\%; (2) Daun dicuci dengan akuades; (3) Daun direnda Daun diNO3 50\% dicuci dengan aquades; (5) Daun dikerik dengu silet: (6) Daun dicuci kembali dengan akuades; (7) Daun direndam sayatan daun dicuci dengan akuades kembali; (9) Sayatan daun diwarnai dengan safranin 1\%:(10) Sayatan daun diletakkan di an safranin 1\%; (10) Sayat diberikan larutan diserin $30 \%$; (11) Sayat diamati di bawah mikroskop. Karakter yang diata mengacu pada penelitian Sulassih et al (2013) dan Hafiz et al. (2013), yaitu sel epidermis (bentuk, ukuran, dinding sel) dan stomata (tipe, ukuran, kerapatan dan indeks). Indeks dan (tipe, ukuran,

dihitung berdasarkan rumus Willmer (1983):
$\mathrm{KS}=\overline{\text { luas }}$

Keterangan

KS: Kerapatan Stoma

IS: Indeks Stomata

Luas bidang pandang $=\pi r^{2} ; \pi$ konstanta $(3,14)$,

jari-jari mikrometer objek

Pengamatan Data Sekunder. Data sekunde yang diamati antara lain, kondisi lingkungan tumbu berupa tipe iklim dan curah hujan. Cara perbanyakan tanamandancaraperawatan tanamandiperolehmelal wawancara dengan pengelola kebun buah manggi TBM dan pihak lain yang terkait.

\section{HASILDAN PEMBAHASAN}

Gambaran Umun Tanaman Manggis dan Kerabatnya di Taman Buah Mekarsari. Taman Buah Mekarsari merupakan pusat pelestarian plasma nutfahtanaman hortikultura dengan luas kawasan 264 Ha dan 88 Ha dialokasikan sebagai kebun buah (Triseptiyanti 2008). Taman Buah Mekarsari (TBM) secara geografis terletak pada 6-35 ${ }^{\circ} \mathrm{LS}$ dan 52-106 BT dengan emiringatan $0-8 \%$ setaketinge BT nengan kemingan lan tim klim A (basah) dengan curah hujan $2000-4000 \mathrm{~mm} /$ tahun (Suriadikusumah 2014), suhu rata-rata $25^{\circ} \mathrm{C}$ dengan kelembaban relatif $80-90 \%$. Kondisi iklim ini sedikit lebih dingin dan lebih lembab dari kondisi iklim di wilayah persebaran alami manggis. Tanaman manggis tumbuh dari dataran rendah sampai ketinggian $\pm 600 \mathrm{mdpl}$, suhu udara berkisar $38^{\circ} \mathrm{C}-40^{\circ} \mathrm{C}$ (Verheij dan Coronel 1997), curah hujan 1500-2500 mm/tahun dan penyinaran matahari $40 \%-70 \%$.

Koleksi manggis dan kerabatnya di Taman Buah Mekarsari terdiri atas 245 tanaman Garcinia mangostana (mangois bogor) 13 tn Garcin (mundu/mis (mis kuning), 29 tananan G.dulcis ( (manggis huan), dan 74 tanaman G.forbesil (mundar). Koleksi tan G. mangostana, G. celebica dan $G$. dulcis berasal dari Bogor, G. malaccensis dari Medan dan Jambi, dan G. forbesii berasal dari Banjar Baru, Kalimantan Selatan. Koleksi manggis bogor ditanam dari biji dan teknik kaki ganda,G. malaccensis, $G$. orbesii, G. celebica juga ditanam dari biji, sedangkan $G$. dulcis ditanam dari teknik sambung. Tanaman koleksi yang diunggulkan TBM adalah G. mangostana (manggis bogor), karena manfaat dan rasa buahnya yang sudah banyak diketahui oleh masyarakat luas (Reza et al 1994). Lokasi penanaman koleksi manggis dan kerabatnya terdapat di blok $C$ dan D yang masing-masing luasnya 1,5 Ha (Gambar 1).Koleksi $G$. mangostana, G. forbesil dan G. Malaccensis ditanam blok $C$ dengan jarak tanam tidak beraturan. Sedangkan G. celebica dan G. dulcis ditanam di blok D dengan jarak tanam teratur. Terdapat pohon peneduh sengo dan kaliandra diblok $\mathrm{C}$ sementara diblok pon cukup tingi. Fungsi pohon penedh yaitsana sud h cukup tinggi. Fungsi pohon peneduh yaitu menaungi tancerk tanah (Reza etal. 1994), karena baik daun ataupun buah manggis rentan terhadap sengatan matahari (Verheij dan Coronel 1997). Area G. mangostana dan G.forbes di blok $\mathrm{C}$ memiliki pH tanah antara 5.5-6.3, kondis tanah termasuk kering pada rentang kelembapan 1-5\% suhu udara antara $34.7-35.7^{\circ} \mathrm{C}$, kecepatan angin $0 \mathrm{~km} /$ jam, intensitas cahaya matahari antara 300-1079 lux serta kelembapan udara antara 58.2-64.0\%. Sementara area G. malaccensis blok $\mathrm{C}$ memiliki $\mathrm{pH}$ tanah antara 5.4-6.2, kelembapan 1-7 \%, suhu udara antara 36$38.7^{\circ} \mathrm{C}$ kecepatan angin $0 \mathrm{~km} / \mathrm{jam}$ intensitas matahari antara 871-1583 lux, dankelembapan uda 50.5-62.9\% Area penanan G. celebica d G. dus G. chulcis diblo D mi elembapan $1 \%$, suhu udara $30-30.2^{\circ} \mathrm{C}$, kecepatan ngin $194-233 \mathrm{~km} / \mathrm{jam}$, intensitas cahaya mataha 75. $75.1 \%$. Menurut Purwanto (2008) tanah yang baik . berkisar 5-7. Pupuk yang digunakan pada tanaman koleksi tersebut yaitu pupuk kandang, dan sebagai tambahan pupuk anorganik seperti sp 36, HCL, dan dolomit.Pupuk-pupuk tersebut diberikan sehabis panen. Pengendalian hama pada tanaman dilaksanakan engan penyemprotan dengan pestisida diantarany decis, furacron, regrent, dan marshal Pestisida tersebu

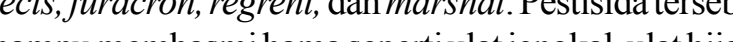
a but dan kutu pulh yang menerang tong yerang tanaman manggis dan kerabatnya di TBM.

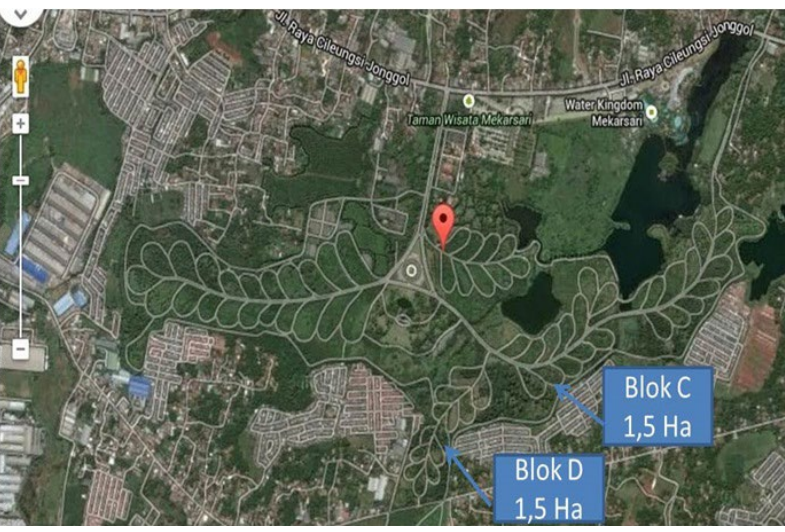

Gambar 1. Peta menunjukkan lokasi kebun manggis da Hak C dan blok D di Taman Buah Mekarsari 
Karakter Morfologi Tanaman Manggis dan Tanaman manggis dan kerabatnya, G. malaccensis Kerabatnya Deskriptor Pertumbuhan. Kondisi dan G. forbesii, berasal dari semai biji dan berumu pertumbuhan tanaman digambarkan dengan beberapa sama namun G. malacensis lebih pendek dan kurus karakter morfologi, seperti karakter batang dan dengan percabangan jarang Sebaliknya G. celebica pesaman mervariasidalamkaraktertipetajuk theg matidak (Gambar 2), arah percabangan(Gambar3), permukaan dipangkas dan dijadikan sebagai pohon peneduh taman, batang(Gambar4), serta perawakanpertumbuhan(Tabel sedangkantanamanmanggis dan spesieskerabatlainny 1). Manggis dan kerabatnya yang dikoleksi di TBM dipangkas agar buahnya lebih mudah dipanen. Selai sudah berumur 12-25 tahun, berasal dari perbanyakan itu, pemangkasan yang tepat akan mengarahkan energ dengan generatif(biji) dan vegetatif(sambung pucuk). pertumbuhanyangtersediauntuk produksibuahsehingga Tanamanmanggisdi TBMmemilikitinggi8-12m, masih hasil panen meningkat (Reza et al. 1994). Tanaman $G$. dalam kisaran tinggi pada umumnya 6-25 $\mathrm{m}$ (Verheij dulcis berasal dari bibit sambung dan baru berumur 12 dan Coronel 1997).

$$
\text { tahun, tetapi memiliki lingkar batang lebi }
$$

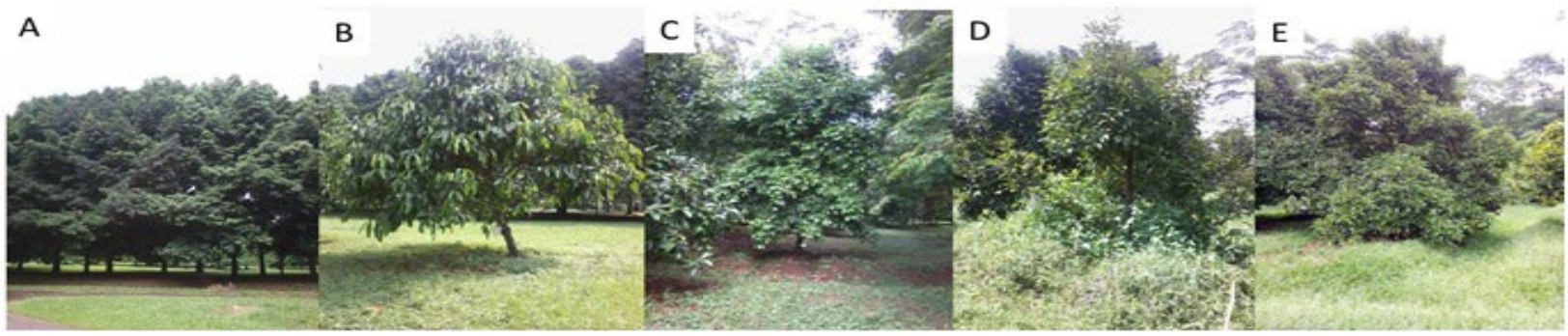

Gambar 2. Variasi tipe tajuk: piramid pada G. celebica(A), G. dulcis(B), G. forbesii(C), G.mangostana(E); oval pada G. dulcis(B) G. forbesii(C),dan G. malaccensis (E)

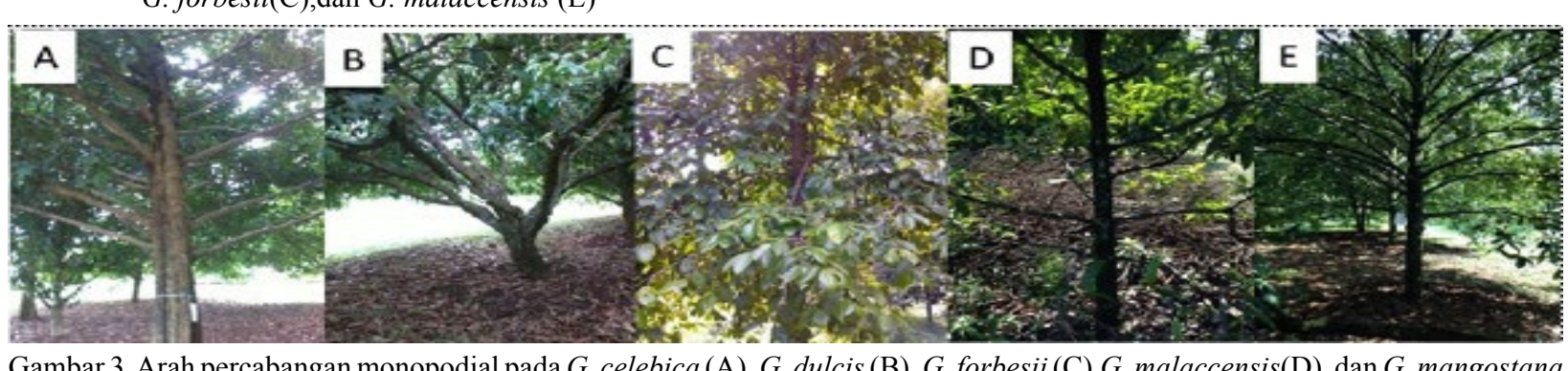

列 (E); simpodial pada G. dulcis (B)

Tabel 1. Morfologi batang dan percabangan koleksi manggis dan kerabatnya di Taman Buah Mekarsar

\begin{tabular}{llllll}
\hline Karakter & G. celebica & G. dulcis & G. forbesii & G. malaccensis & G. mangostana \\
\hline - Umur tanaman & 22 tahun & 12 Tahun & 25 Tahun & 25 Tahun & 25 Tahun \\
- Tipe perbanyakan & Semai biji & Sambung & Semai Biji & Semai Biji & Semai Biji \\
- Kekekaran tanaman & Tinggi & Medium & Medium & Rendah & Medium \\
- Tinggi batang & $6-15 \mathrm{~m}$ & $1.5-9.5 \mathrm{~m}$ & $6-8 \mathrm{~m}$ & $1.5-3 \mathrm{~m}$ & $4.5-7.5 \mathrm{~m}$ \\
- Tinggi tanaman & $11.5-20.5 \mathrm{~m}$ & $8-16 \mathrm{~m}$ & $8-10.5 \mathrm{~m}$ & $3-4.5 \mathrm{~m}$ & $8-12 \mathrm{~m}$ \\
- Lingkar batang & $102-154 \mathrm{~cm}$ & $80-104.4 \mathrm{~cm}$ & $38.4-77 \mathrm{~cm}$ & $20.5-42.8 \mathrm{~cm}$ & $50.4-59.8 \mathrm{~cm}$ \\
- Permukaan batang & Sangat kasar & Halus & Halus & Kasar & Kasar \\
- Tipe tajuk & Piramid & Piramid-Oval & Piramid-Oval & Oval & Piramid \\
- Perawakan tanaman & Tegak lurus & Tegak Lurus & Tegak Lurus & Tegak Lurus & Tegak Lurus \\
- Kepadatan percabangan & Tebal & Tebal & Jarang & Jarang & Tebal \\
- Bentuk batang & Gilig & Gilig & Gilig & Gilig & Gilig \\
- Tipe percabangan & Monopodial & Monopodial-Simpodial & Monopodial & Monopodial & Monopodial \\
- Arah percabangan & Horizontal & Setengah Tegak & Horizontal & Horizontal & Horizontal \\
\hline
\end{tabular}

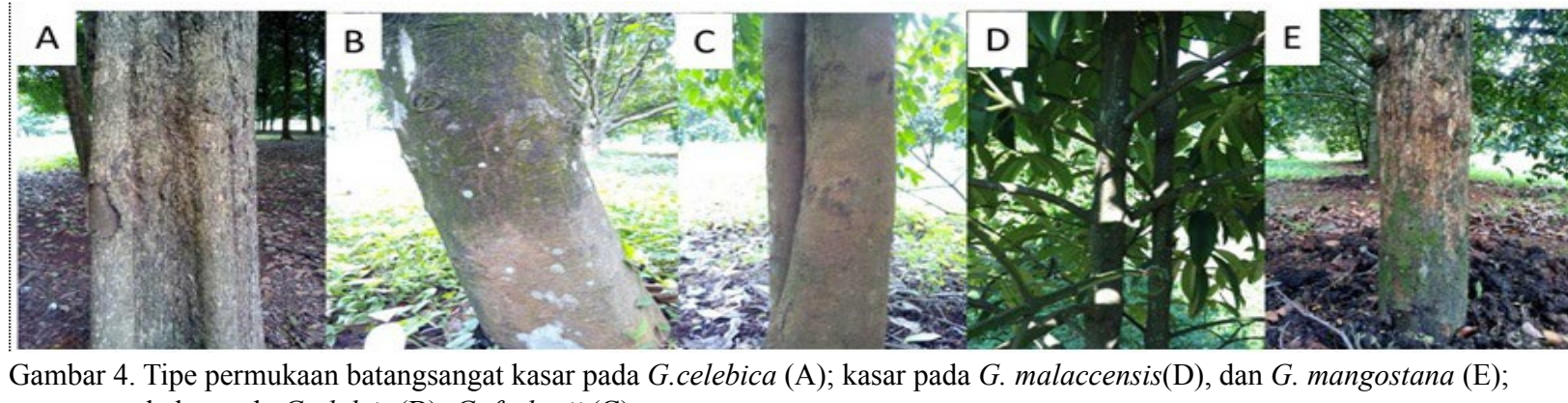
Tipe permukaan batangsangat kasar pada
halus pada $G$. dulcis (B), G. forbesii (C)

Daun. Tanaman manggis dan kerabatnya dan merah kecokelatan(G.forbersii)(Tabel2). Bentuk memiliki susunan daun berhadapan bersilangan, daun daunjuga bervariasi, bulat telur terbalik, lonjong-lonjong tua berwarna hijau tua, tepi daun rata, permukaan menyempit, lanset (Gambar 5). Bentuk daun bulat atas dan bawah daun mengkilat, ibu tulang daun telur terbalik hanya dijumpai pada $G$ forbesii. Hasil jelas denen penelitia G. dulcis), hijau muda dengan semburat kecokelatan Hartuti 2008). (G. mangostana, G. celebica, G. dulcis, G. forbersii),

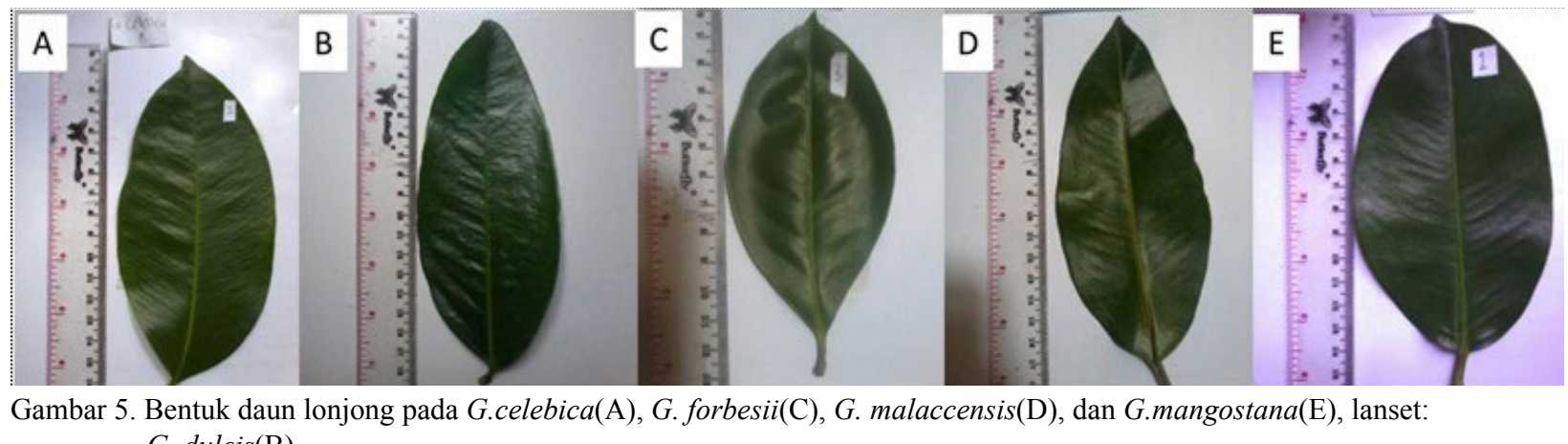
G. $\operatorname{dulcis}(\mathrm{B})$

Tabel 2. Morfologi daun koleksi manggis dan kerabatnya koleksi di Taman Buah Mekarsari

\begin{tabular}{|c|c|c|c|c|c|}
\hline Karakter Daun & G. celebica & G. dulcis & G. forbesii & G. malaccensis & G. mangostana \\
\hline - Susunan & $\begin{array}{l}\text { Berhadapan } \\
\text { bersilangan }\end{array}$ & $\begin{array}{l}\text { Berhadapan } \\
\text { Bersilangan }\end{array}$ & $\begin{array}{l}\text { Berdahapan } \\
\text { Bersilangan }\end{array}$ & $\begin{array}{l}\text { Berhadapan } \\
\text { Bersilangan }\end{array}$ & Berhadapan Bersilangan \\
\hline - Kerapatan & Rapat & Rapat & Medium & Medium & Rapat \\
\hline - Panjang tangkai & $1.3-2.4 \mathrm{~cm}$ & $1.2-2.8 \mathrm{~cm}$ & $1.1-2 \mathrm{~cm}$ & $0.7-1.8 \mathrm{~cm}$ & $0.4-2.1 \mathrm{~cm}$ \\
\hline - Lebar tangkai & $0.3-0.5 \mathrm{~cm}$ & $0.2-0.4 \mathrm{~cm}$ & $0.1-0.2 \mathrm{~cm}$ & $0.25-0.45 \mathrm{~cm}$ & $0.45-0.55 \mathrm{~cm}$ \\
\hline - Bentuk lembaran & $\begin{array}{l}\text { Lonjong-Lon- } \\
\text { jong menyempit- } \\
\text { Lanset }\end{array}$ & $\begin{array}{l}\text { Lanset Telur- } \\
\text { Lonjong } \\
\text { Menyempit- } \\
\text { Lanset-Lonjong }\end{array}$ & $\begin{array}{l}\text { Bulat Telur } \\
\text { Terbalik-Lonjong }\end{array}$ & $\begin{array}{l}\text { Lonjong-Lonjong } \\
\text { Menyempit-Lanset }\end{array}$ & $\begin{array}{l}\text { Lonjong-Lonjong } \\
\text { Menyempit }\end{array}$ \\
\hline - Panjang lembaran & $14-22.5 \mathrm{~cm}$ & $17.4-26.2 \mathrm{~cm}$ & $10.5-16.5 \mathrm{~cm}$ & $10.2-18.2 \mathrm{~cm}$ & $14-22.2 \mathrm{~cm}$ \\
\hline - Lebar lembaran & $6-9.8 \mathrm{~cm}$ & $4.6-10.6 \mathrm{~cm}$ & $4.7-6.7 \mathrm{~cm}$ & $4.4-7.4 \mathrm{~cm}$ & $6.7-10.2 \mathrm{~cm}$ \\
\hline - Ujung daun & $\begin{array}{l}\text { Meruncing- } \\
\text { Runcing-Tumpul }\end{array}$ & Meruncing & Meruncing & Meruncing & Meruncing \\
\hline - Pangkal daun & $\begin{array}{l}\text { Runcing- } \\
\text { Tumpul-Asimetri }\end{array}$ & $\begin{array}{l}\text { Tumpul- } \\
\text { Runcing- } \\
\text { Asimetri }\end{array}$ & $\begin{array}{l}\text { Meruncing- } \\
\text { Asimetri-Tumpul }\end{array}$ & $\begin{array}{l}\text { Runcing- } \\
\text { Meruncing- } \\
\text { Asimetri-Tumpul }\end{array}$ & Meruncing-Memotong \\
\hline - Warna daun muda & Hijau Muda & $\begin{array}{l}\text { Hijau Muda- } \\
\text { Hijau Muda } \\
\text { dengan Semburat } \\
\text { Kecokelatan }\end{array}$ & $\begin{array}{l}\text { Hijau Muda } \\
\text { dengan Semburat } \\
\text { Kecokelatan- } \\
\text { Merah } \\
\text { Kecokelatan }\end{array}$ & Hijau Muda & $\begin{array}{l}\text { Hijau Muda-Hijau } \\
\text { Muda dengan Semburat } \\
\text { Kecokelatan }\end{array}$ \\
\hline - Warna daun tua & Hijau Tua & Hijau Tua & Hijau Tua & Hijau Tua & Hijau Tua \\
\hline
\end{tabular}


Bunga. Garcinia termasuk tanaman berumah dua pada tanaman yang berbeda. Reproduksi Garcinia bersifat fakultatif agamospermy, yaitu reproduks dengan biji tetapi pembentukan embrio tidak melalu embuahn(Sulassih etal 2013). Pada sat peneliti

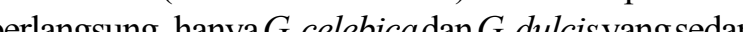
berbuna (Gambar 6), tanam tersebut meredang

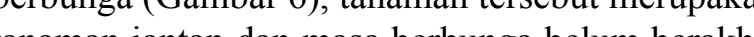
(t) sampai dengan penelitian ini selesai. Tanaman janta spesies kerabat manggis menniliki periode berbung yang panjang dan berbunga lebih dari satu kali dala setahun (Te-chato 2007). Bunga betina tidak ditemuka pada saatpenelitian karena sudah terbentuk buah. Bunga Jantan G. celebica terdapat pada ujung cabang dan memiliki sepal dan petal 4 , sedangkan bungajantan $G$. dulcis terdapat di ketiak daun dan memiliki sepal dan petal 5 (Tabel3). Dua spesies kerabat manggis tersebut memiliki sepal kuning dan petal kuning putih, tetap G. celebica memiliki ukuran bunga lebih besar dari $G$. dulcis (Tabel 3). Jumlah sepal dan petal 4 ditemuk .

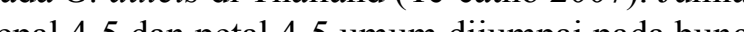
pepal 4-5 das petal 4-5 una dijunpai pada bunga manggis dan kerabatnya (Verhelj dan Cornel 1997). Benang sari pada G. celebica banyak, tersusun dalam 4 berkas (11-39 per berkas) dengan androfor pendek sedangkan pada $G$. dulcis sedikit, tersusun dalam berkas (4-10 per berkas) dengan androfor panjang (Tabel 3). Putik dengan kepala putik menyegi empa tetapi ovari tereduksi dijumpai pada bunga jantan $G$. celebica. Putik dengan ovari tereduksi dan kepala putik berlobus dijumpai pada bunga jantan spesies G. mangostana (Te-catho 2007). Pada bunga janta spesies kerabat manggis lainnya, seperti $G$. dulcis, tidak dijumpai putik yang tereduksi. Bunga jantan $G$. celebica mirip dengan bunga jantan $G$. mangostan celebica mirip diliki androfor jantan . mangostan

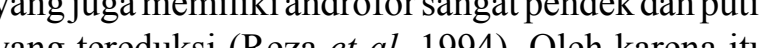
yang tereduksi (Reza et al. 1994). Oleh karena itu, G. celebica memiliki hubungan kekerabatan yang dekat dengan G. mangostana (Sulassih et al. 2013). Viabilitas polen sangat rendah pada bunga jantan $G$. mangostana $(0.1-1 \%)$ dan $0 \%$ pada bunga jantan $G$. dulcis ditemukan pada hasil penelitian di Thailan (Te-chato 2007). Hal ini membuktikan ciri reproduksi agamospermy pada tanaman manggis dan spesies kerabatnya.

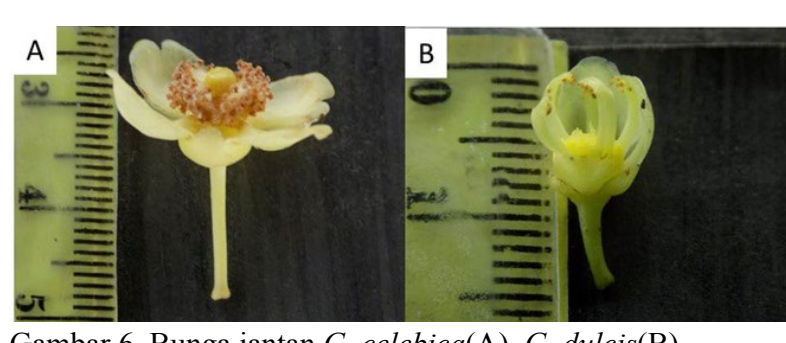

3. Morfologi bunga jantan G. celebica dan G. dulcis di

\begin{tabular}{|c|c|c|}
\hline Karakter & G. celebica & G. dulcis \\
\hline $\begin{array}{l}\text { - Keteraturan } \\
\text { berbunga }\end{array}$ & $\begin{array}{l}\text { Puncak musim } \\
\text { berbunga pada } \\
\text { bulan Juni }\end{array}$ & $\begin{array}{l}\text { Puncak musim } \\
\text { berbunga pada } \\
\text { bulan Juni }\end{array}$ \\
\hline - Durasi berbunga & 2 bulan & 2 bulan \\
\hline $\begin{array}{l}\text { - Kelimpahan } \\
\text { bunga }\end{array}$ & Sedang & Melimpah \\
\hline - Posisi bunga & Ujung & Ketiak \\
\hline $\begin{array}{l}\text { - Pengelompokkan } \\
\text { bunga }\end{array}$ & Bunga soliter & $\begin{array}{l}1,2,3 \text { atau lebih } \\
\text { bunga perkelom- } \\
\text { pok }\end{array}$ \\
\hline - Ukuran bunga & Besar & Kecil \\
\hline - Panjang tangkai & $1.5-1.9 \mathrm{~cm}$ & $0.3-0.9 \mathrm{~cm}$ \\
\hline $\begin{array}{l}\text { - Jumlah dan } \\
\text { warna sepal }\end{array}$ & 4, Kuning & 5, Kuning \\
\hline $\begin{array}{l}\text { - Jumlah dan } \\
\text { warna petal }\end{array}$ & 4, Kuning putih & 5, Kuning putih \\
\hline $\begin{array}{l}\text { - Jumlah berkas } \\
\text { benang sari }\end{array}$ & 4 & 5 \\
\hline $\begin{array}{l}\text { - Jumlah benang } \\
\text { sari perberkas }\end{array}$ & $11-39$ & 04-10 \\
\hline - Panjang androfor & $0.1 \mathrm{~cm}$ & $0.8 \mathrm{~cm}$ \\
\hline
\end{tabular}

Buah. Buah merupakan perkembangan lebih lanjut dari bakal buah. Buah manggis dan buah dari spesies kerabatnya termasuk buah buni karena buah berasal dari satu bunga dengan ovari yang berkembang menjadi kulit buah (pericarp) yang tebal berdaging. Bagian buah manggis yang biasanya dikonsums adalah bagian salut (aril) biji Tanaman mang yang bera 1 ri biji baru buli 10-15 tan aat pendin berrangsung alah G. celebca, G. dulcis tan berlangsung adalah G. celebica, G. dulcis dan G. forbesii (Gambar 7). Tanaman $G$ malaccensis dan manggis sedang tidak berbuah. Manggis dan kerabatnya merupakan tanaman berbuah musiman, dan musim berbuah berbeda antar daerah (Darmawansyih 2014). Musim panen buah manggis di Indonesia umumnya berlangsung pada bulan November-Desembersedangkan di Malaysia da Thailand musim panen berlangsung pada bulan JuniJuli (Muslim dan Nura 2011).Musinberuh dapat dipengaruhioleh faktor lingkungan hujan Pada saat penelitian (bulan Septemb Dese. Pada saat penelitian (bulan September hingga Desember) spesies G. mangostana,G. malaccensis tidakmengalami pembungaan dan tidak menghasilkan buah, hal ini mungkin berhubungan dengan curah hujan yang tinggi pada bulan-bulan sebelumnya yaitu 301-400 mm/hari (BMKG 2016). Hal tersebut membenarkan penelitian Muslim dan Nurasa (2011) yang menyatakan bahwa musim penghujen dapat menurunkan produksimanges.

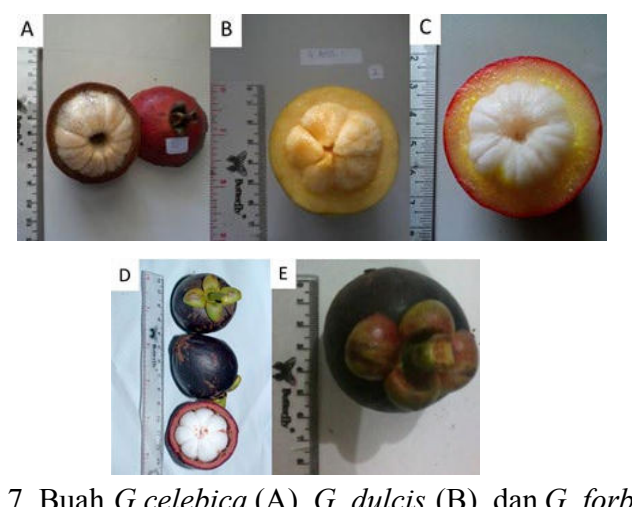

Gambar 7. Buah G.celebica (A), G. dulcis (B), dan G. forbesii (C),

Bentuk buah G. dulcis bulat telur terbalik, ujung runcing dengan lobus kepala putik yang kecil dan mudah gugur (Tabel 4). Buah G. forbesii bulat dengan pangkal rata, dan ujung cekung dengan lobus kepala putik. Buah G. celebica bulat dan dengan ujung mempunyai tonjolan yang mendukung lobus kepala putik. Buah $G$. forbesii dan $G$. celebica memiliki warna kulit matang berwarna merah, namun $G$ forbesii memiliki warna merah yanglebih terang. G. for besii puth saju, G. celebica pu in kren pada . forbesi puin sand G. celebica puth ken dan $G$. ulcis kuning terang. Buah $G$. forbesil memiliki aril yang rasanya asam manis. Buah $G$. forbersil lebih asam jika dibandingkan dengan manggis pada umumnya, tetapi memiliki kelebihan, yaitu kulit buahnya dapat dimakan dan dapat diolah sebagai pengganti asam jawa. Tanaman $G$. dulcis di TBM memiliki buah yang rasanya asam sekali, tetapi ditemukan beberapa pohon yang memiliki buah manis. Koleksi tanaman yang berbuah manis ini dapat dikembangkan sebagai kultivar ungoul Buah G. dulcis yang mempunyai rasa manis dapat dimakan dan dijadikan buah komersil (Utami dan Sari 2009). Buah G.celebica memiliki rasa yang asam dan cenderung pahit, oleh sebab itu koleksi tanaman $G$. celebica di TBM tidak dimanfaatkan untuk menghasilkan buah untuk tujuan komersial. Namun spesies kerabat manggis ini memiliki sistem perakaran dan batang yang kuat dan cocok sebagai bibit sambung. Buah G. celebica mempunyai biji yang berbentuk elips, $G$. dulcis mempunyai bentuk biji yang lebih bervariasi yaitu bulat, elpis dan lonjong dan cenderung lebih tebal dari spesies kerabatnya, sedangkan $G$ forbesii mirip dengan G. celebica teta (etapi memiliki ketebalan biji yang lebih tipis (Gambar 8).

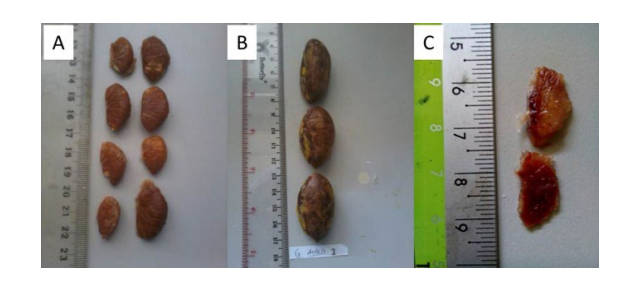

Gambar 8. Biji buah G.celebica (A), G. dulcis (B), G. forbesii koleksi di Taman Buah Mekarsari

\begin{tabular}{|c|c|c|c|}
\hline Karakter & G. celebica & G. dulcis & G. forbesii \\
\hline $\begin{array}{l}\text { - Panjang } \\
\text { tangkai }\end{array}$ & $0.9-1.9 \mathrm{~cm}$ & $1.1-2.1 \mathrm{~cm}$ & $0.4-0.5 \mathrm{~cm}$ \\
\hline $\begin{array}{l}\text { - Kekuatan } \\
\text { tangkai }\end{array}$ & Kuat & Kuat & Kuat \\
\hline $\begin{array}{l}\text { - Warna } \\
\text { tangkai }\end{array}$ & Hijau & Hijau & Cokelat \\
\hline $\begin{array}{l}\text { Warna } \\
\text { getah }\end{array}$ & Putih & Kuning & Kuning \\
\hline $\begin{array}{l}\text { - Bentuk } \\
\text { buah }\end{array}$ & Bulat & $\begin{array}{l}\text { Bulat-Bulat } \\
\text { telur }\end{array}$ & $\begin{array}{l}\text { Bulat rata } \\
\text { pada ujung } \\
\text { dan pangkal }\end{array}$ \\
\hline $\begin{array}{l}\text { - Ukuran } \\
\text { buah }\end{array}$ & Kecil & Besar & Kecil \\
\hline • Panjang & $3.5-5.5 \mathrm{~cm}$ & $4-7 \mathrm{~cm}$ & $5-4 \mathrm{~cm}$ \\
\hline - Diameter & $3.5-5.7 \mathrm{~cm}$ & $4.7-8 \mathrm{~cm}$ & $3.3-4.2 \mathrm{~cm}$ \\
\hline • Berat & $33-64 \mathrm{~g}$ & $58-177 \mathrm{~g}$ & $30-52 \mathrm{~g}$ \\
\hline $\begin{array}{l}\text { - Lobus } \\
\text { kepala putik }\end{array}$ & Persistence & Persistence & Persistence \\
\hline $\begin{array}{l}\text { - Kedudukan } \\
\text { lobus kepala } \\
\text { putik }\end{array}$ & $\begin{array}{l}\text { Menumpang } \\
\text { pada tonjolan } \\
\text { buah yang } \\
\text { rompang }\end{array}$ & $\begin{array}{l}\text { Menumpang } \\
\text { pada tonjolan } \\
\text { buah yang } \\
\text { runcing }\end{array}$ & $\begin{array}{l}\text { Tenggelam } \\
\text { dalam } \\
\text { cekungan }\end{array}$ \\
\hline $\begin{array}{l}\text { - Warna } \\
\text { kepala putik }\end{array}$ & Co kelat & $\begin{array}{l}\text { Cokelat- } \\
\text { Hitam }\end{array}$ & Merah \\
\hline $\begin{array}{l}\text { - Warna } \\
\text { kulit matang }\end{array}$ & Merah tua & $\begin{array}{l}\text { Kuning } \\
\text { terang }\end{array}$ & Merah terang \\
\hline $\begin{array}{l}\text {-Ketebalan } \\
\text { kulit buah }\end{array}$ & $\begin{array}{l}\text { Tipis }(0.3 \\
\mathrm{cm})\end{array}$ & $\begin{array}{l}\text { Tebal (0.8-1 } \\
\mathrm{cm})\end{array}$ & $\begin{array}{l}\text { Tebal }(0.8- \\
1 \mathrm{~cm})\end{array}$ \\
\hline $\begin{array}{l}\text { - Jumlah } \\
\text { segmen aril }\end{array}$ & $7-9$ & $4-5$ & $5-8$ \\
\hline - Warna aril & Putih salju & $\begin{array}{l}\text { Kuning } \\
\text { lemon- } \\
\text { Kuning Tua }\end{array}$ & Putih salju \\
\hline - Tebal aril & $3 \mathrm{~mm}$ & $3 \mathrm{~mm}$ & $4-5 \mathrm{~mm}$ \\
\hline $\begin{array}{l}\text { - Terkstur } \\
\text { aril }\end{array}$ & Kuat & Menengah & Kuat \\
\hline $\begin{array}{l}\text { - Total } \\
\text { padatan } \\
\text { terlarut }\end{array}$ & 11-19.3 "brix & $\begin{array}{l}7.2-18.1 \\
\text { obrix }\end{array}$ & 9-16 brix \\
\hline $\begin{array}{l}\text { - Aril flavour } \\
\text { (aroma) }\end{array}$ & Menengah & Menengah & kuat \\
\hline $\begin{array}{l}\text { Aril taste } \\
\text { (rasa) }\end{array}$ & Asam pahit & Asam-Manis & Asam manis \\
\hline $\begin{array}{l}\text { - Kadar air } \\
\text { pada aril }\end{array}$ & Berair & Berair & Berair \\
\hline - Tipe Biji & Elips & $\begin{array}{l}\text { Bulat-Elips- } \\
\text { Lonjong }\end{array}$ & Elips \\
\hline - Tebal Biji & $0.4-1.1 \mathrm{~cm}$ & $1.3-1.5 \mathrm{~cm}$ & $01-0.2 \mathrm{~cm}$ \\
\hline - Warna Biji & Coklelat & Cokelat & Cokelat \\
\hline - Jumlah Biji & 4-8 & 3-4 & \\
\hline
\end{tabular}


Karakter Anatomi Tanaman Manggis dan Spesies Kerabatnya.

Bentuk dan Ukuran Sel Epidermis. Daun bagia abaksial dan adaksial dari spesies Garcinia yang diama memiliki sel epidermis yang sama, yaitu berbentuk persegi sampai persegi panjang. Variasi bentuk dinding sel epidermis dijumpai pada spesies-spesies yang diamati. Dinding berlekuk zig-zag dalam dijumpai pada sel epidermis daun G. forbesii, sedangkan spesies lainnya memiliki sel epidermis dengan dinding rat hingga berlekuk dangkal (Gambar 10).Hasil yang
sama dilaporankan oleh Sulassih et al. (2013) pada sama dilaporankan oleh Sulassih et al. (2013) pada Ukuran sel epidermis daun manggis dan kerabatny dengan lebar rata-rata dari $13.9(\mu \mathrm{m})$ hingga 21.37 $(\mu \mathrm{m})$, den panjang rata-rata dari $29.1(\mu \mathrm{m})$ hingga $34.22(\mu \mathrm{m})($ Tabel 5).

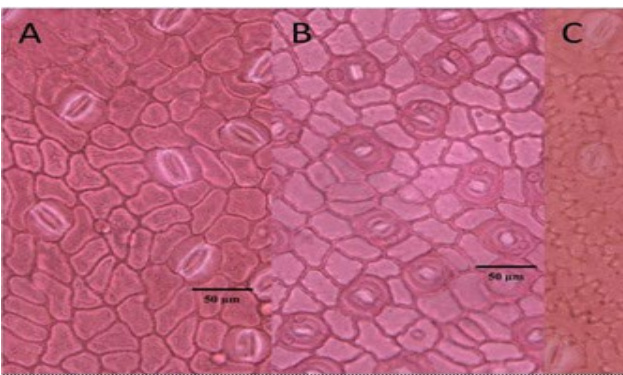
(A), G. dulcis (B),G. forbesii (C), G. malaccensis (D), dan G. mangostana (E)

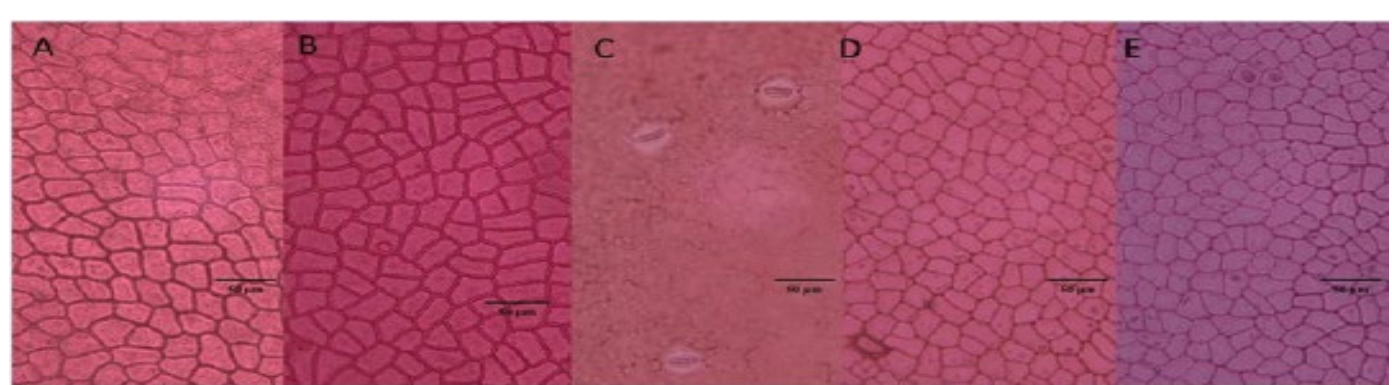

Gambar 10. Sayatan paradermal daun bagian adaksial koleksi manggis dan spesies kerabatnya di Taman Buah Mekarsari: $G$ celebica (A), G. dulcis (B),G forbesii (C), G. malaccensis (D), den G. mangostana (E)

Tabel 5. Rata-rata dan standar deviasi dari kerapatan dan indeks stomata,lebar dan panjan sel epidermis daunmanggis dan spesies kerabatnya di Taman Buah Mekarsari

\begin{tabular}{llllll}
\hline Spesies & $\begin{array}{l}\text { Bagian Permukaan } \\
\text { Daun }\end{array}$ & $\begin{array}{l}\text { Kerapatan Stomata } \\
\left(/ \mathrm{mm}^{2}\right)\end{array}$ & Indeks Stomata & Lebar Epidermis & Panjang Epidermis \\
\hline G. forbesii & Adaksial & $21.69 \pm 2.18$ & $1.98 \pm 0.23$ & $21.31 \pm 0.67$ & $32.62 \pm 4.33$ \\
G. forbesii & Abaksial & $123.36 \pm 11.97$ & $13.86 \pm 1.35$ & & \\
G. celebica & Abaksial & $108.62 \pm 4.87$ & $9.04 \pm 0.4$ & $21.37 \pm 3.39$ & $31.86 \pm 4.29$ \\
G. dulcis & Abaksial & $281.47 \pm 47.1$ & $16.3 \pm 1.14$ & $14.88 \pm 1.54$ & $34.22 \pm 3.07$ \\
G. malaccensis & Abaksial & $137.36 \pm 6.13$ & $7.54 \pm 0.3$ & $13.47 \pm 1.03$ & $29.1 \pm 3.09$ \\
G. mangostana & Abaksial & $152.33 \pm 32.61$ & $8.65 \pm 1.52$ & $13.9 \pm 0.89$ & $37.58 \pm 2.57$ \\
& & & & & \\
\hline
\end{tabular}

\section{SIMPULAN}

Simpulan. Manggis dan empat spesies kerabatnya merupakan tanaman perenial dan berbuah musiman, memiliki karakter morfologi batang gilig dengan percabangan monopodial, tajuk berbentuk piramid, elips dan oval. Cirikhas untukmembedakanantarspesies manggis dan kerabatnya adalah karakter bunga dan buah. Buah spesies kerabat manggis memiliki bentuk, warna kulit matang, dan rasa yang berbeda dengan buah manggis pada umumnya. Karakter anatomi paradermal daun menunjukkan persamann tipestomata pada semua spesies yang diamati yaitu parasitik dengan bentuk sel epidermis yang sama yaitu persegihingga persegi panjang. Sel epidermis pada G. celebica, G. dulcis, G. malaccensis, dan G. mangostana memiliki dinding rata hingga berlekuk dangkal, sedangkan dinding berlekuk dalam dan zig-zag dijumpai pada sel epidermis daun G. forbesii.

\section{DAFTAR PUSTAKA}

[BPS] Badan Pusat Statistik. 2017. Produksi tanaman buah-buah [internet]. Tersediapada:https://www.bps.go.id/site/resultTab.

[BMKG] Badan Meteorologi, Klimatologi dan Geofisika. 2016. Buletin Analisis Hujan Bulan Januari2016 dan Prakiraan hu Bulan Maret, April dan Mei 2016 [internet]. Tersediapd

http://bogor.jabar.bmkg.go.id/diseminasi/publikasi/.
Darmawansyih. 2014. Khasiat buah manggis untuk kehidupan. $A l$ Hikmah. 15(1): 60-67.

[IPGRI] International Plant Genetic Resources Institute. 2003. Descriptor for Mangosteen (Garciniamangostana). Rome (IT): International Plant Genetic ResourcesInstitute.

Hariani S. 2014. Efektivitas ekstrak daun mundu (Garcinia dulcis) sebagai larvasi dan yamuk Culexquinquefasciatus dan Aedes aegypti [skripsi]. Bogor (ID): InstitutPertanian Bogor

Hafiz P, Dorly, Rahayu S. 2013. Karakteristik anatomi dari kekerabannya Buletin Kebun Raya 16(1):58-73.

Harrison JL, Leong L, Sia G, Sim K, Tant HTW. 1993. Xantones
from Garcinia forbesii. Phytochemistry.33(3): 727-728.

Hartuti S. 2008. Studi keragaman morfologi populasi bibit manggis (Garcinia mangsotana L.) asal empatsentra di kabupaten
Tasikmalaya [skripsi] Bogor (ID): Institut Pertanian Bogor. Jamal Y, Praptiwi, Agusta A. 2001. Penampisan fitokimia, uji toksisitas dan anti bakteri dari ekstrak kulitbatang G.celebica
dan G.tetandra. Buletin Farmasi Indonesia 12(2):97-102. dury AS, Fakhrunnisa F, Amin A. 2012. Pemanfatan kulit Madury AS, Fakhrunnisa $\mathrm{F}$, Amin A. 2012. Pemanfaatan kulit
manggis (Garcinia mangostana $\mathrm{L}$ ) sebagai formulasi tablet A Metcalfe CR, Chalk L. 1957. Anatomy of The Dicotyledons. London (GB): Oxford University Pr.

Muslim C, Nurasa T. 2011. Daya saing komoditas promosi ekspor manggis, sistem pemasaran dan kemantapannyadidalam negeri.

Pongpaichit S, Rungindamai N, Rukachaisirikul V, Sakayaroj
J.2006.Antimicrobial activity inculturesofendophytic fungi isolated from Garcinia species. FEMSImmunol MedMicrobiol. 48:367-372.
PurwantoA. 2008. Kajian macam eksplan dan konsentrasiiba terhadap multiplikasi tanaman manggis (Garcinia mangsotana L.) secar . mangois Jakarta(ID): Penebar Swadaya.

danhistokimia rimpang temulawak (CurcumaxananthorrizoRoxb) [skripsi]. Bogor (ID): Institut Pertanian Bogor

Sass JE. 1951. Botanical Microtechnique. Iowa (US): Iowa Stage Collage Pr.

Sinaga S. 2008. Analisis keanekaragaman genetik dan fenotip manggis (Garcinia mangostana L.) dankerabat dekatnya [disertasi]. Sulassih, Sobir, Santosa E. 2013. Phylogenetic analysis of mangosteen (Garcinia mangostana L.) and itsrelatives based on morphological and inter simple sequence repeat (ISSR) markers. SABRAO Journal of Breeding and Genetics. 45(3): $478-490$

Suriadikusumah A. 2014. Ekowisata dan agrowisata (ekogrowisata) alternative solusi untuk pengembangan wilayah (ID):Univ-lahan berlering di Jawa Barat[skripsi]. Bandung (ID):Universitas Padjajaran.

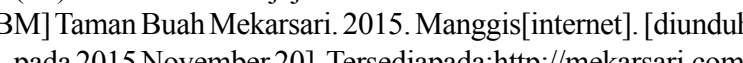
aher M, Susanti D, Rezali FM, Zohri ASF, Ichwan AJS, Alkhamaise SI, Ahmad F. 2012. Apoptosis,antimicrobial and antioxidan activities of phytochemicals from Garcinia malaccensis $\mathrm{Hk}$. Asian Pacific Journal of Tropical Medicine.136-141.

e-chato S. 2007. Floral and fruit morphology of some spesies Garcinia Spp. Songklanakarin J. Sci. Technol.29(2): 245-252. kebun buah di Taman MekarsariBogor [skripsi] Bogor(ID): Institut Pertanian Bogor.

Utami N, Sari R. 2009. Mundu: Garcinia xanthochymus Hook.f. atau G. dulcis (Roxb.) Kurz.?. Berita Biologi. 9(6): 739-734. Verheij EWM, Coronel RE. 1997. Sumber Daya Nabati Asia Tenggara 2: Buah buahan yang dapat Dimakan. Danimihard, S, Sutarno H, Utami NW, Hoesen DSH, penerjemah; Verheif Wh, Coronel RE, editor. Jakarta (ID): Gramedia Pustal 2. Edible Fruits and Nuts. Widiastuti A, Sobir, dan Suhartanto SM. 2010. Analisis keragaman manggis (Garcinia mangostana) diiradiasi denga sinargammaberdasarkan karakteristikmorfologidan anatomi Nusantara Bioscience. 2(1): 23-33.

Willmer CM. 1983. Stomata. London (UK): Longman Group Ltd 